\title{
Numerical Simulations for Average Temperature Differential Stirling Engine
}

\author{
Khaled M. Bataineh*
}

Department of Mechanical Engineering, Jordan University of Science and Technology, Irbid-Jordan

\begin{abstract}
A second order mathematical model taken into account thermal losses for average temperature differential Stirling engine is developed. Dynamic simulation of the engine based on mathematical formulation is carried out under different operating and geometrical conditions to investigate the engine performance. The developed model is used to investigate the influence of geometrical and physical parameters on the performance of Stirling engine. Design optimization of Stirling engine is carried out. Finally optimal parameters have been determined.
\end{abstract}

Keywords: Stirling engines, dynamic model, thermal losses, performance, numerical simulations.

\section{INTRODUCTION}

The Stirling engine was invented by Robert Stirling in 1816 [1]. Due to limited amount of non-renewable sources in the world, the harm effect on the environment resulted from using non-renewable energy sources and high oil prices, the world forced to search for alternative clean infinite energy sources [2-4]. Utilizing solar energy is one of the promising methods to provide auxiliary clean energy. Since the Stirling engines can use any external heat source, for example solar power, regain interest in these engines has been recently witnessed. Stirling engines are considered very attractive due to their ability to use any external heat source and the high efficiency. A Stirling engine is considered an external combustion engine which has a working gas inside of it. This gas is sealed inside of the engine and used to transform heat to work. Heating and cooling the working gas cause the movement of the piston and provide mechanical energy.

In Stirling engine, a cold gas is compressed, and then is heated to further increase the pressure. The work can be obtained by expanding the hot high pressure gas. Finally, the gas is cooled before it gets compressed for the next cycle to begin. Stirling engine has six major components; heat source, heater, regenerator, heat sink, cooler, piston/displacer and chambers. Heat transfer to the working fluid is very important. Regenerator is the key to the Stirling engine performance. The main purpose of the regenerator is to increase the Stirling engine efficiency by decrease the amount of heat required at the heater. However, increasing heat transfer rate in the regenerator is

*Address correspondence to this author at the Department of Mechanical Engineering, Jordan University of Science and Technology, Irbid-Jordan; Tel: +962 27201000 Ext. 22383; Fax: +962 2 7201074;

E-mail:k.bataineh@just.edu.jo accompanied by unwanted increase in dead space and pumping losses. So in practice, this conflict limits the total efficiency of a Stirling engine.

The actual efficiency of the Stirling engine is still very low when compared to the theoretical efficiency. This is due to that the theoretical investigations did not accurately describe the complex behavior associated with heat transfer and fluid flow processes occurring Stirling engine. An accurate description and understanding of these highly non-stationary phenomena is necessary so that different engine losses and optimal design parameters can be determined. The performance of Stirling engines using finite-time thermodynamic analysis and the effect of heat losses and irreversibilities on engine performance have been studied by several authors [5-12]. Urieli and Berchowitz developed an adiabatic model and a quasistationary model where they introduced only the pressure drops into the exchangers [11]. Even though the model developed by Urieli and Berchowitz predicted more accurate results compared to other models, however, their predictions are different from the corresponding experimental data [11]. The results presented by Popescu et al. revealed that the most substantial decrease in the performance is due to the nonadiabatic regenerator [5]. The studies of $[6,14]$ found that the most important factors affecting the performance of a Stirling engine are; finite heat conductance between the engine and its reservoirs, the imperfect regeneration, and the finite rates of the two regenerating processes. Kongtragool and Wongwises investigated theoretically the effect of regenerator effectiveness and dead volume on the engine performance [8]. Costea studied the solar - powered Stirling engines; they concluded that the internal irreversibility affect the operating temperature and the performance of the engine [15]. Cheng and Yang [16] studied theoretically the effects of the geometrical 
parameters on the shaft work of the Stirling engines. They obtained optimal combination of the phase angle and the swept volume ratio under different specified conditions that leads to maximization of the shaft work of the engine. The results obtained by the model developed by [17] that account for losses are correlated more closely with the corresponding experimental data than other models.

\section{THERMODYNAMICS OF STIRLING CYCLE}

The ideal Stirling engine has the maximum possible mechanical efficiency. Ideal Stirling engine has thermal efficiency equals to the Carnot cycle. Also reasonable amount of work can be obtained without the necessity to use very high pressure and large swept volume due to large P-V diagram area. The Stirling cycle is based on two opposing pistons in motion as shown in Figure 1. Ideal Stirling cycle consists of two isothermal and two isochoric processes (Figure $\mathbf{2 a}$ and $\mathbf{b}$ ). During the isothermal compression process 1-2 (heat transfer from working fluid at low temperature to an external sink), the cold piston moves towards the regenerator. In constant-volume heating process 2-3 (heat transfer to the working fluid from regenerator), both pistons move similarly so that the volume remains constant. During isothermal expansion process (3-4) (heat transfer to the working fluid at high temperature from hot source), only the hot piston is moving during this process. Finally, constant-volume cooling process 4-1 (heat transfer from the working fluid to the regenerator), both pistons move in order to keep the volume constant and to transfer the working fluid through the regenerator.
The mathematical analysis of Stirling engine is complicated. Schmidt was the first to perform an analysis of the Stirling engine [16]. He assumed that the expansion and compression spaces were isothermal. It has been showed that using ideal isothermal analysis to predict the performance of a Stirling engine leads to paradox stating that heat exchangers are unnecessary and all the heat can be transferred across the boundaries of the working spaces. To avoid this paradox, adiabatic expansion and compression processes should be enforced to prevent heat transfer across the boundaries of these two spaces. This analysis was developed by Urieli where he assumed that the gas in the cylinder undergoes an adiabatic process rather than an isothermal process [13]. This analysis is called an ideal adiabatic analysis. However, this type of analysis is not very realistic because compression and expansion are not adiabatic and since it does not take into account the several losses which negatively degrade the engine performance. It is found that practical Stirling cycle always differs significantly from the ideal cycle mainly due to the imperfect regeneration and finite heat transfer in heat exchanger. Some detailed analysis with practical values and examples of the engine are given by Organ [19].

Previous studied have focused on high or low temperature Stitrling engine. Mean temperature Stirling engine has not received significant attention. Striling engines operating under mean temperature do not require careful expensive material selection nor do they require high-cost hot source system. These advantages make Stirling engines very attractive and

regenerator

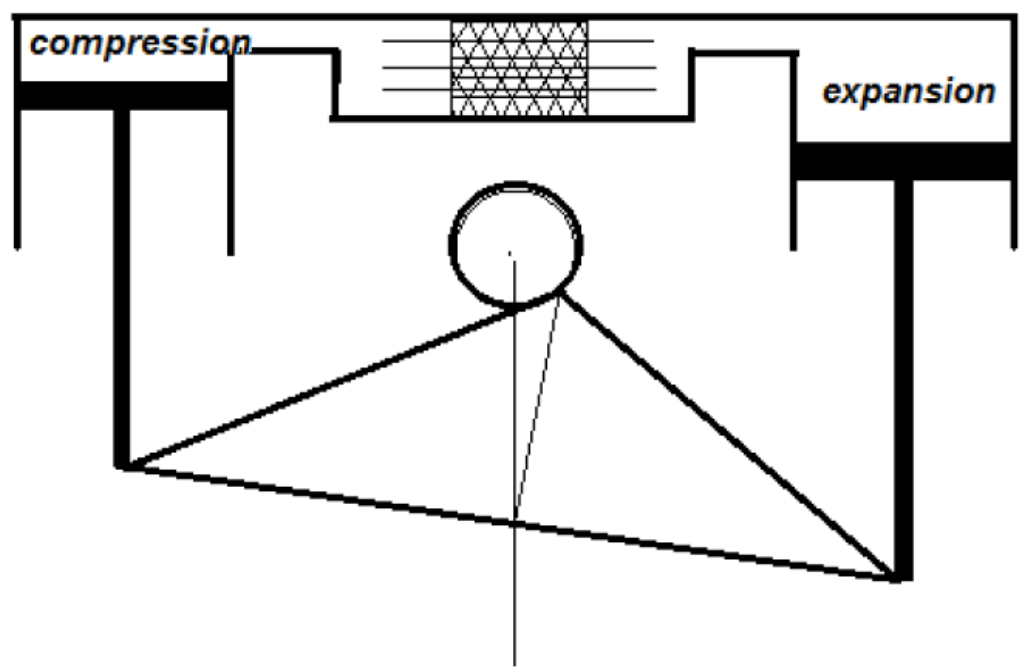

Figure 1: Ross Yoke Stirling engine. 
promising in terms of reliability and cost. The objective of this study is to develop more realistic approach that accurately predicts engine performance. This approach should include pumping losses due to friction, imperfection in regeneration, thermal losses in expansion and compression spaces. The performance of the engine is indicated in terms of output power and thermal efficiency. Heat transfer (thermal network) analysis in Stirling engine will be conducted. The influence of major parameters on the maximum power output and the corresponding overall efficiency are analyzed in detail. These parameters include, but not limited to, gas type, volumes, temperatures, mean pressure, frequency, heater, cooler and regenerator. Furthermore, this paper presents design optimization so that Stirling engines can achieve higher efficiency while maintaining high power output. Finally, this article presents technical design guidelines for mean temperature differential Stirling engine.

\section{STIRLING ANALYSIS}

The objective of this study is to analyze the engine performance in terms of net power output and efficiency. An accurate model should be created in

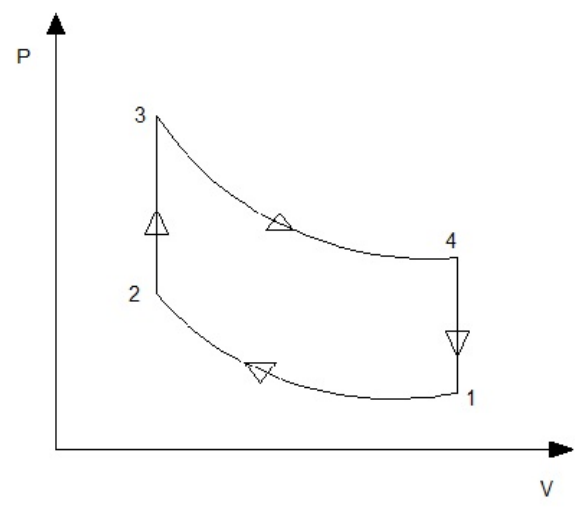

a : Ideal adiabatic P-V diagram

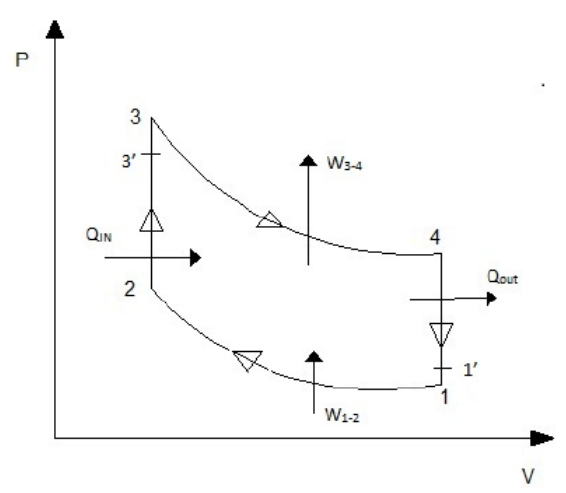

c: Non- ideal regenerator P-V diagram order to accurately predict the engine performance. For this study, a nodal analysis of Alpha -type engine is performed. The Stirling engine is divided into 5 control volumes; compression, cooler, regenerator, heater, and expansion as shown in Figure $\mathbf{3}$ (top). The control volumes of compression $V_{c}$ and expansion $V_{e}$ spaces are variable. The other control-volumes have fixed volumes. The energy, state equation and mass equations are written for each engine volumes. The energy analysis is considered to evaluate the amount of heat transfer between the working gas, heat source, and sink. To simplify the model, we assume:

1. The working gas is an ideal gas,

2. Constant total mass inside the engine,

3. Adiabatic compression and expansion spaces,

4. Empirical equations are used to model heat transfer and flow friction in the heat exchangers.

5. The cooler and the heater walls are maintained isothermally at temperatures $T_{k-w}$ and $T_{h-w}$ respectively,

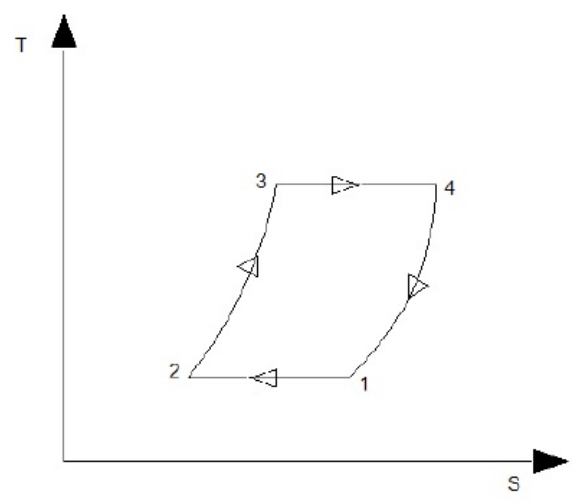

b: Ideal T-S diagram

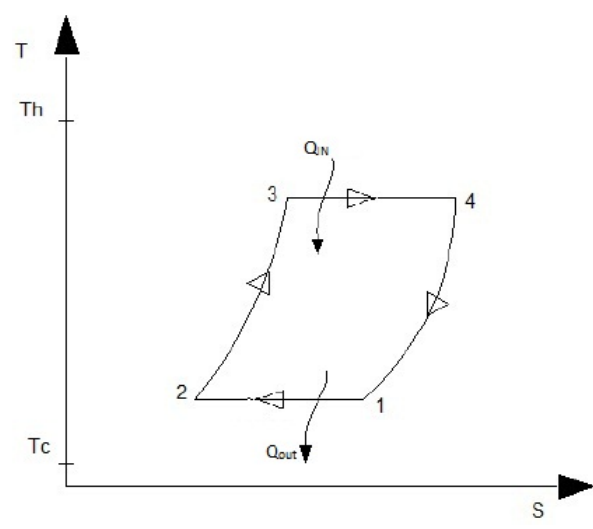

d: Non- ideal regenerator T-S diagram

Figure 2: $\mathrm{P}-\mathrm{V}$ and T-S diagrams for ideal and non- ideal regenerator. 


\section{Temperature within the regenerator varies linearly between $T_{h}$ and $T_{k}$, \\ 7. Variable gas temperature in the engine compartments is assunmed.}

The temperature distribution in the various engine compartments is illustrated in Figure $\mathbf{3}$ (bottom). The temperature of the mass flow between the cooler and the regenerator is $T_{c}$ independent on the flow direction. Also, the temperature between the regenerator and the heater is $T_{h}$ independent on the flow direction. Discontinuities in temperature occur at the compression -cooler and expansion -heater interfaces. These discontinuities first described by Finkelstein [20] that require the following conditional statements:

$$
\text { If } \dot{m}_{1}>0 \text { then } T_{1}=T_{k} \text { else } T_{1}=T_{c}
$$$$
\text { If } \dot{m} 4>0 \text { then } T_{4}=T_{h} \text { else } T_{4}=T_{e}
$$

The general form of the conservation of energy principle in each control volume after ignoring kinetic and potential energy is:

$$
d Q+\left(\dot{m}_{i} c_{p} T_{i}-\dot{m}_{o} \mathrm{C}_{\mathrm{p}} T_{\text {out }}\right)=d W+c_{v} d(m T)
$$

From mass conservation, the rate of accumulation of gas in compression $\left(d m_{c}\right)$ is equal to the mass inflow of gas:

$$
d m_{c}=\dot{m} 1
$$

And the partial work done by the compressor on the working fluid is:

$d W_{c}=P d V_{c}$

Assuming adiabatic compression, the energy balance in the compression space reduced to:

$-c_{p} T_{1} d m_{c}=P d V_{c}+c_{v} d\left(T_{c} m_{c}\right)$

The equation of state and the associated ideal gas relations are:

$$
P V=m R T, h=c_{p} T, u=c_{v} T, R=c_{p}-c_{v}, \gamma=\frac{c_{p}}{c_{v}}
$$

If we substitute the ideal gas law and the associated ideal gas relations for the compression space, change in the mass is given by:

$$
d m_{c}=\frac{P d V_{c}+V_{c} d P / \gamma}{R T_{1}}
$$

Similarly, the change in mass in expansion space is given by:
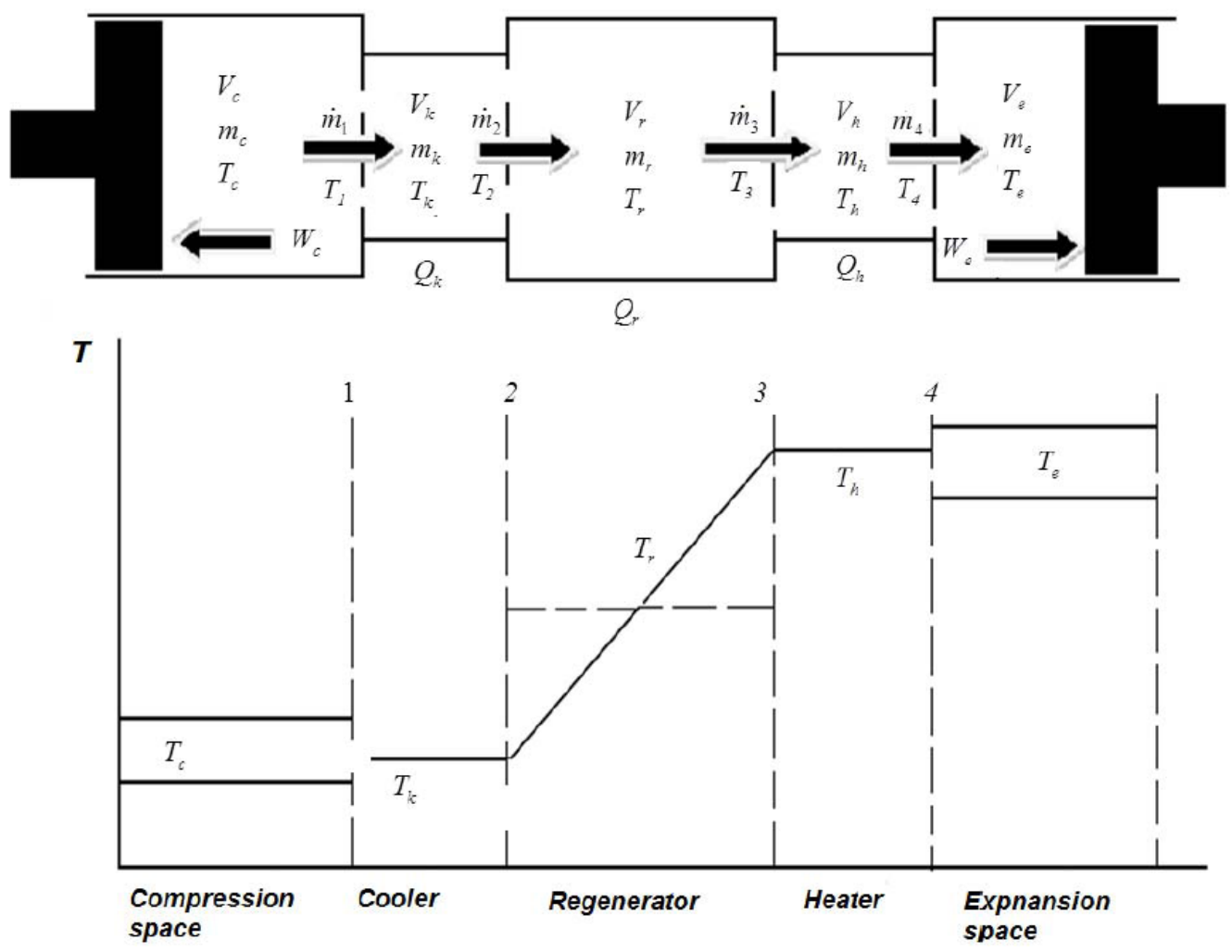

Figure 3: Schematic diagram of Stirling engine and temperature distribution. 
$d m_{e}=\frac{P d V_{e}+V_{e} d P / \gamma}{R T_{4}}$ by:

The differential form of the equation of state is given

$\frac{d P}{P}+\frac{d V}{V}=\frac{d m}{m}+\frac{d T}{T}$

Since the volumes and temperature are constants in the three heat exchangers the differential equation of state reduces to:

$\frac{d P}{P}=\frac{d m}{m}$

Then change in mass for the three heat exchangers is given by:

$d m=\frac{m d P}{P}=\frac{V d P}{R T}$

$d m_{c}=\frac{m_{c} d p}{P}, d m_{r}=\frac{m_{r} d p}{P}, d m_{h}=\frac{m_{h} d p}{P}$

The total mass of the working gas is given as:

$M$ tot $=m_{c}+m_{k}+m_{r}+m_{h}+m_{e}$

If there is no leakage, the total mass is conserved, differentiate equation (14):

$d m_{c}+d m_{k}+d m_{r}+d m_{h}+d m_{e}=0$

Substituting equation 13 for the heat exchangers in equation 16, this yields:

$d m_{c}+d m_{e}+\frac{d P\left(V_{c} / T_{c}+V_{r} / T_{r}+V_{k} / T_{h}\right)}{R}=0$

Where $T_{r}$ is regenerator mean effective temperature which can be calculated as follow; experimentally, for homogeneous regeneration, a linear variation of the temperature versus the position has been observed [8]. Assume the regenerator has a linear temperature distribution across its length $L_{r}$ varies from $T_{k}$ to $T_{h}$. The mean effective temperature of the regenerator is determined as follows:

$T(z)=\frac{T_{h}-T_{k}}{L_{r}} z+T_{k}$,

Using ideal gas law $r=p / R T_{r}$, the mass in a differential volume $A d z$ at location $z$ is:

$d m=r d V=\frac{p A d z}{R T_{r}}=\frac{p A d z}{R \frac{\left(T_{h}-T_{k}\right)}{L_{r}} z+T_{k}}$
The total mass in the regenerator volume $A L_{r}$ is

$$
\begin{aligned}
& m_{r}=\frac{p V_{r}}{R} \int_{0}^{V_{r}} \frac{1}{\left(T_{h}-T_{k}\right) z+L_{r} T_{k}} d x=\frac{V_{r} p \ln \left(T_{h} / T_{k}\right)}{R\left(T_{h}-T_{k}\right)} \\
& \Rightarrow T_{r}=\frac{\ln \left(T_{h} / T_{k}\right)}{\left(T_{h}-T_{k}\right)}
\end{aligned}
$$

We can use the regenerator temperature for all mechanical calculations, i.e., to determine pressure. Substituting the mass change in the compression and expansion spaces, respectively, together with the mass changes in heater exchangers, the change in pressure is now given by:

$$
d P=\frac{-\gamma P\left(\frac{d V_{c}}{T_{1}}+\frac{d V_{e}}{T_{4}}\right)}{\frac{V_{c}}{T_{1}}+\gamma\left(\frac{V_{c}}{T_{c}}+\frac{V_{r}}{T_{r}}+\frac{V_{h}}{T_{h}}\right)+\frac{V_{e}}{T_{h}}}
$$

The differential temperatures for the expansion and compression spaces formulated from the differential form of the equation of state are given by:

$$
d T_{c}=T_{c}\left(\frac{d P}{P}+\frac{d V_{c}}{V_{c}}-\frac{d m_{c}}{m_{c}}\right)
$$

$d T_{e}=T_{e}\left(\frac{d P}{P}+\frac{d V_{e}}{V_{e}}-\frac{d m_{e}}{m_{e}}\right)$

Using ideal gas relations, the energy equation for the cooler, heater and regenerator space can be reduced to following differential equations:

$$
\begin{aligned}
& d Q_{k}=\frac{c_{v} V_{k} d P}{R}-c_{p}\left(T_{1} \dot{m}_{1}-T_{2} \dot{m}_{2}\right) \\
& d Q_{h}=\frac{c_{v} V_{h} d P}{R}-c_{p}\left(T_{3} \dot{m}_{3}-T_{4} \dot{m}_{4}\right) \\
& d Q_{r}=\frac{c_{v} V_{r} d P}{R}-c_{p}\left(T_{2} \dot{m}_{2}-T_{3} \dot{m}_{3}\right) \\
& \text { Where } \begin{array}{l}
\dot{m}_{4}=-d m_{e} \\
\dot{m}_{2}=\dot{m}_{1}-d m_{k} \\
\dot{m}_{3}=\dot{m}_{4}+d m_{h}
\end{array}
\end{aligned}
$$

Note that for ideal regenerator and isothermal heat exchanger, $T_{2}=T_{k}, T_{3}=T_{h}$

\subsection{Expression of Losses}

Previous equations are derived based on ideal adiabatic model which could not correlate closely to the 
experimental results. In order to accurately model the thermal behavior of Stirling engine and to find the optimal design parameters, the model has to take into account the heat losses, irreversibilities effect on the engine and the critical flaws of the regenerator. Forced convection heat transfer is the main heat transfer mechanism. Heat exchangers should be designed very compact but efficient. This increases the friction and as a result an extra mechanical power is required to transport the working gas through the heat exchangers. Spending this extra power to compensate for the friction, we have less output power from the engine. This reduction in the output power is referred to as "pumping loss". Analyzing this effect is very complex and relies on many factors. Some experimental results have to be used as the only mean to do a simple analysis. The shuttle losses and losses by irreversibility effect of the compression and the relaxation have little influence on the performances and therefore have been ignored.

\subsubsection{Reheat Loss}

The performance of regenerator heat exchanger can be represented by the effectiveness $\varepsilon$ which defined as:

$\varepsilon=\frac{\text { actual enthalpy change in a single stroke }}{\text { maximum theoritical enthalpy change in a single stroke }}$

The effectiveness of regenerator ranges between zero (no regeneration) and one for ideal regeneration. For the non- ideal regenerator, the energy stored by the regenerator when the gas from the expansion space passes to the compression space is not totally returned by the gas in its way back. The outlet fluid temperature coming out of the regenerator in a half cycle is less than the temperature of the heater. It follows that the heater must provide an extra heat called $Q_{r}$ which causes a reduction in the efficiency. The situation is the same for the cooler.

$$
\begin{aligned}
& Q_{h}=Q_{h-\text { ideal }}+Q_{r-\text { ideal }}(1-\varepsilon) \\
& Q_{k}=Q_{k-\text { ideal }}-Q_{r-\text { ideal }}(1-\varepsilon) \\
& Q_{r}=(1-\varepsilon)\left(Q_{r-\text { ideal }}-Q_{r-\min }\right)
\end{aligned}
$$

$Q_{r}$ is the thermal power related to the regenerator inefficiency. The effectiveness of a regenerator can be evaluated in terms of the input and output temperature. Assuming linear temperature profile with equal temperature difference in cold and hot side, simplified expressions of $\varepsilon$ with respect to number of heat transfer unit NTU can be found in the literature. Expression of $\varepsilon$ given by [21] is adopted in this study:

$\varepsilon=\frac{N T U}{1+N T U}$

Where NTU is equal to $\frac{h A_{w t}}{C_{p} \dot{m}}$. The NTU value is a function of heat exchanger type and size. The NTU can be written as a function of heat exchanger dimension and Stanton number:

$$
N T U=\frac{A w t}{A} S t
$$

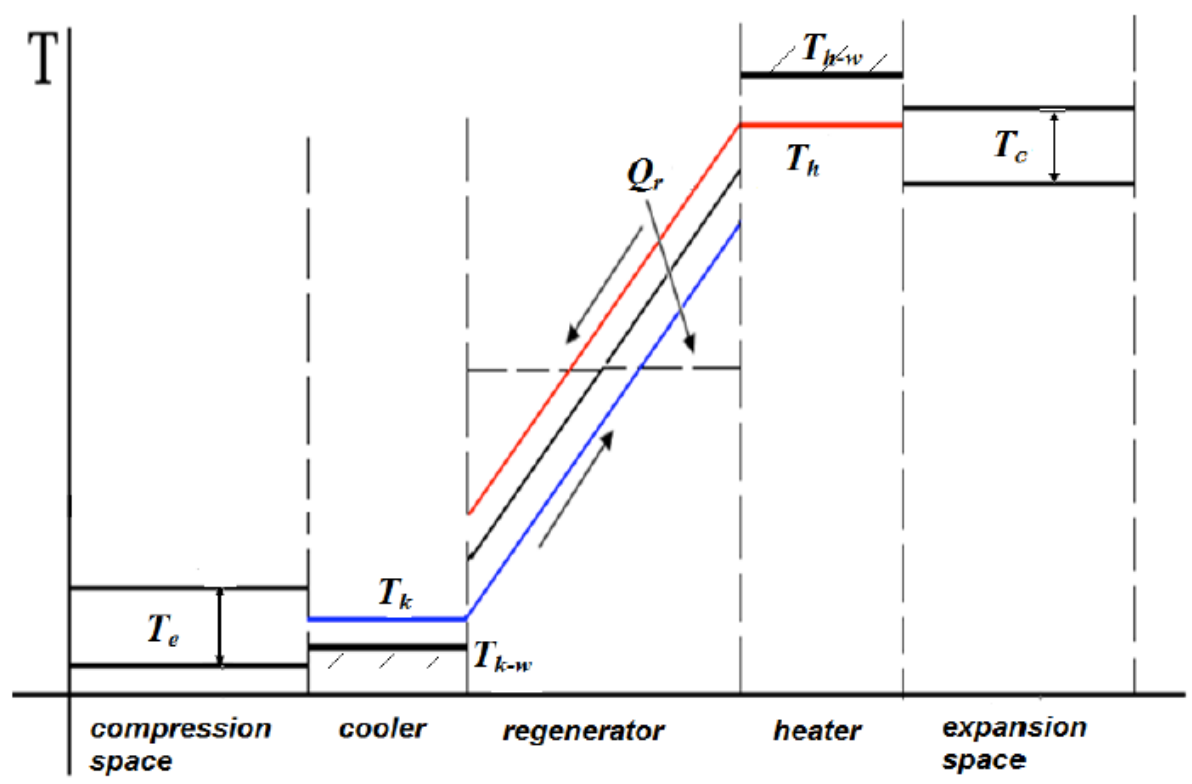

Figure 4: Real temperature profile for heat transfer analysis. 
Where $S_{t}$ is Stanton number can be found experimentally for different type of heat exchangers.

\subsubsection{Cooler and Heater Losses}

Since the actual heat exchangers are not ideal, the mean temperature of the cooler is higher than its wall temperature and the heater temperature is lower than its wall temperature as shown in Figure 4. This has a negative effect on the engine performance due to the resulted smaller temperature difference between the hot and the cold space.

Heat is transferred to the working gas by means of forced convection given by:

$\dot{Q}=h A_{w t}\left(T_{w}-T\right)$

Evaluating the heat transfer in the cooler and heater and finding the energy loss in the regenerator then:

$Q_{h}=\frac{h_{h} A_{h-w t}\left(T_{h-w}-T_{h}\right)}{f_{r}}+Q_{r-l o s s}$

$Q_{k}=\frac{h_{k} A_{k-w t}\left(T_{k-w}-T_{c}\right)}{f_{r}}-Q_{r-\text { losss }}$

Where, $Q_{r-\text { loss }}$ is the enthalpy loss in regenerator, $h_{h}, h_{k}$ is the heat transfer coefficients of exchanges and $A_{k-w t}$ and $A_{h-w k}$ are the wetted areas of the cooler and heater respectively.

Based on experimental correlations, $\mathrm{h}$ is expressed as a function of the Colburn J-factor Jh [21].

$J h(R E)=\frac{h \operatorname{Pr}^{2 / 3}}{C_{p} \dot{m} / A_{f f}}$

Where, $\mathrm{Pr}$ is the Prandtl number and $\mathrm{A}_{\mathrm{ff}}$ the free flow area. The evolution of $J_{h}$ with respect to $R e$ is of the form

$J h(\operatorname{Re})=C \operatorname{Re}^{-n}$

The heat transfer coefficients are available only empirically [13].

The energy loss in the regenerator is:

$Q_{r-\text { loss }}=(1-\varepsilon)\left(Q_{r-\max }-Q_{r-\min }\right)$

\subsubsection{Mechanical Losses}

Mechanical losses must also be considered to calculate global efficiency. Great friction force generated within kinematic linkages. Pressure drops due to fluid flow through heat exchangers and regenerator is considered another source of mechanical dissipation. This loss is due to friction and to area changes and is called pumping loss which reduces the engine net power. In order to find this loss, the pressure drop can be calculated using the friction factor coefficient related to the Reynolds number given by [9]:

$\Delta P=-\frac{2 f \mu u V}{d^{2} A}$

Where $f$ is the Reynolds friction factor, $u$ is the fluid bulk velocity, $V$ is the volume of the heat exchanger, $d$ is hydraulic diameter. The Reynolds friction factor $f$ is determined from experimental data presented in the charts. The hydraulic diameter defined as the ratio between void volume and wetted area is given by:

$d=\frac{V}{A_{w t}}$

Where $A_{w t}$ is the wetted area equals to the interior area of the heat exchanger which is in contact with the working gas.

\subsection{Thermal Efficiency}

The ideal thermodynamic efficiency is exactly the Carnot efficiency:

$\eta_{\text {ideal }}=1-\frac{T_{k}}{T_{h}}$

The thermal efficiency of an ideal adiabatic engine is:

$\eta_{\text {ideal }}=\frac{W_{\text {ideal }}}{Q_{h-\text { ideal }}}=\frac{Q_{h-\text { ideal }}+Q_{k-\text { ideal }}}{Q_{h-\text { ideal }}}$

This equation gives the efficiency for an ideal regenerator with effectiveness equals to one. However, in practice, the effectiveness is less than one, and hence the thermal efficiency is now given by:

$\eta=\frac{W}{Q}=\frac{Q_{h}+Q_{k}}{Q_{h}}=\frac{1}{1+(1-\varepsilon)\left(\frac{Q_{r-\text { ideal }}}{Q_{h-\text { ideal }}}\right)} \eta_{\text {ideal }}$

The total work in the compression and expansion spaces is:

$W=W_{c}+W_{e}=\oint P d V_{c}+\oint P d V_{e}$ 
The energy loss due to friction can be expressed as loss in the work as follows

$\oint(P-\Sigma \Delta P) d V_{e}$

Then the network over a complete cycle is given by:

$$
\begin{aligned}
& \mathrm{W}=\oint P d V_{c}+\oint(P-\Sigma \Delta P) d V_{e}= \\
& \oint P\left(d V_{c m p}+d V_{\exp }\right)-\oint \Sigma \Delta P d V_{\exp }=W_{a d}-\Delta W
\end{aligned}
$$

Where $W_{a d}$ is the work obtained from the ideal adiabatic model and $\Delta W$ is the sum of the losses in the three heat exchangers given by:

$$
\Delta W=\int_{0}^{2 \pi}\left(\left(\Delta P_{h}+\Delta P_{r}+\Delta P_{c}\right) \frac{d V_{e}}{d \theta}\right) d \theta
$$

\section{METHOD OF SOLUTION}

The independent 16 differential equations obtained in previous section are solved simultaneously for the unknown variables such as mean pressure, temperature, mass, density of working gas, heat transfers and the mechanical etc, over a complete cycle. These equations are considered as ordinary differential equations and are formulated as an initial value problem. Then they are integrated over a "quasistatic flow" condition by using numerical methods. If the vector $Y$ denotes the unknown functions, and the initial conditions to be satisfied are denoted as $Y\left(t_{0}\right)=Y_{0}$, then the corresponding set of differential equations is expressed as $d Y / d t=F(t, Y)$. The objective is to find the unknown function $Y(t)$ which satisfies both the differential equations and the initial conditions. The best method for these equations is runge-kutta forth order method. The solution starts from the stationary state with any arbitrary initial values, and goes through successive transient cycles until the periodic conditions are reached. The initial values of Te \& Tc are unknown and the only obvious thing is that their values are the same at the beginning of each cycle. This fact makes the choice of the initial values has no effect on the results. In the present solution, initial conditions for the engine temperature are set to zero which simulates the warm up period of an engine. Then the integration is performed for several cycles to attain a steady-state condition. Matlab program is built to carry out all these calculations. The answer for all the engine quantities and its performance is represented by a matrix with 22 rows and 73 column for 5 degrees interval.

The input parameters of the engine can be categorized as follow: gas type, volumes of the engine compartments, temperatures, mean pressure, frequency, heater, cooler and regenerator. The performance of the engine is function of these parameters.

\section{ROSS-YOKE ENGINE}

The engine studied in this article uses yoke linkage to drive the pistons. This linkage allows the engine to work without any side forces acting on the cylinder walls by the pistons. The relationship between volume changes and crank angle should be obtained before performing the thermodynamic analysis. The volumes variations are derived from geometric relation as shown in Figure 5 are [13]:

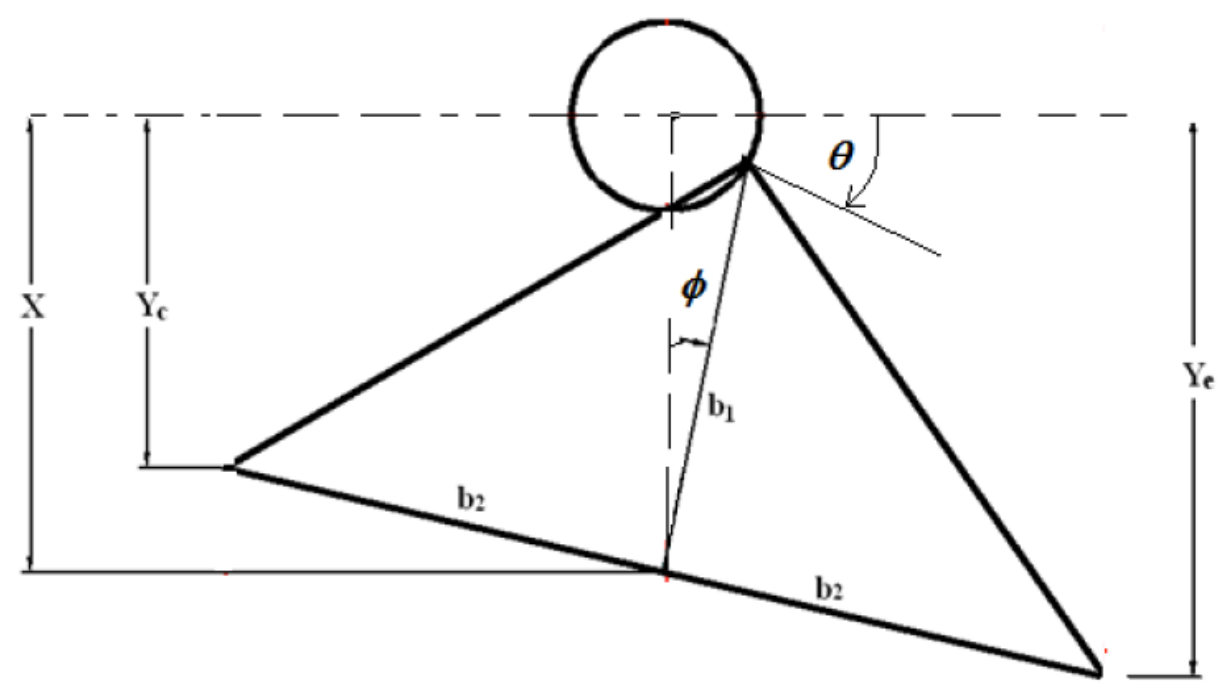

Figure 5: Ross yoke linkage. 


$$
\begin{aligned}
& \text { Yoke }=\sqrt{\left(b_{1}^{2}+b 2^{2}\right)} \\
& y \max =\sqrt{\left(\left(\text { Yoke }+r_{c}\right)^{2}-b 2^{2}\right)} \\
& \theta_{c m p \text { max }}=\boldsymbol{\pi}-\boldsymbol{\theta}_{\text {exp } \max } \\
& y \min =\sqrt{\left(\left(\text { Yoke }-r_{c}\right)^{2}-b 2^{2}\right)} \\
& \theta \operatorname{exp\operatorname {min}}=\pi+\sin ^{-1}\left(\frac{y \min }{\text { Yoke }-r_{c}}\right) \\
& \theta_{c m p \min }=3 \pi-\theta \exp m i
\end{aligned}
$$

for volumes:

$V_{e}=V_{c l e}+A_{e}\left(y_{e}-y_{\min }\right)$

$V_{c}=V_{c l c}+A_{c}\left(y_{c}-y_{\min }\right)$

$\frac{d V c}{d \theta}=A_{c} r\left(\cos \theta+\sin \theta\left(\frac{b 2}{b 1}\right)+\frac{r \sin \theta \cos \theta}{b_{\theta}}\right)$

$\frac{d V e}{d \theta}=A_{e} r\left(\cos \theta-\sin \theta\left(\frac{b 2}{b 1}\right)+\frac{r \sin \theta \cos \theta}{b_{\theta}}\right)$

\section{RESULTS AND DISCUSSION}

Several simulations are performed based on the theoretical analysis to evaluate the effects of the geometric and physical parameters on engine performance. In each simulation, one parameter is changed while we have kept the other parameters unchanged. We start the simulation by plotting P-V diagram (Figure 6). The first deviation from the ideal model can be seen in Figure 6 where it shows that the actual $p-V$ diagram is an elliptical cycle which is different from that predicted by the ideal adiabatic model. This phenomenon can be explained by the fact that the cylinder walls do not have high sufficient conductance to ensure constant gas temperature within the cylinders, thus causes deviation from the isothermal conditions. The area enclosed by the $p-V$ diagram represents the net power developed by the engine. It is clear that the net power predicted by the current approach is less than that of adiabatic assumption.

\subsubsection{Effect of Swept Volume and Dead Volumes}

Figure 7 illustrates the variation of the power output with respect to swept volume for several values of heater temperatures. The swept volume is changed by changing the piston surface while keeping the piston stroke constant. These results were calculated under fixed operating frequency $=90 \mathrm{~Hz}$. It is shown that the power increases when the swept volume increases until an optimal value is reached. Over the optimal swept volume, the output power gradually descends. The values of the optimal swept volume increase with increase in the heater temperature. Also, it is noticeable that the power increases with the increase in the heater temperature. These two remarks imply that we have an optimal value of swept volume for maximum engine power for several heater temperatures.

Dead volume which comes mainly from the heat exchanger (i.e heater and cooler) has significant effect on the engine efficiency. Figures $\mathbf{8}$ and $\mathbf{9}$ illustrate the relationship between the engine power and the dead volume for engine frequency of $90 \mathrm{~Hz}$. The results presented in these figures show that the net power experiences large decrease with the increase in the dead volume. The rate of the net power drop is similar for all heater temperature values studied.

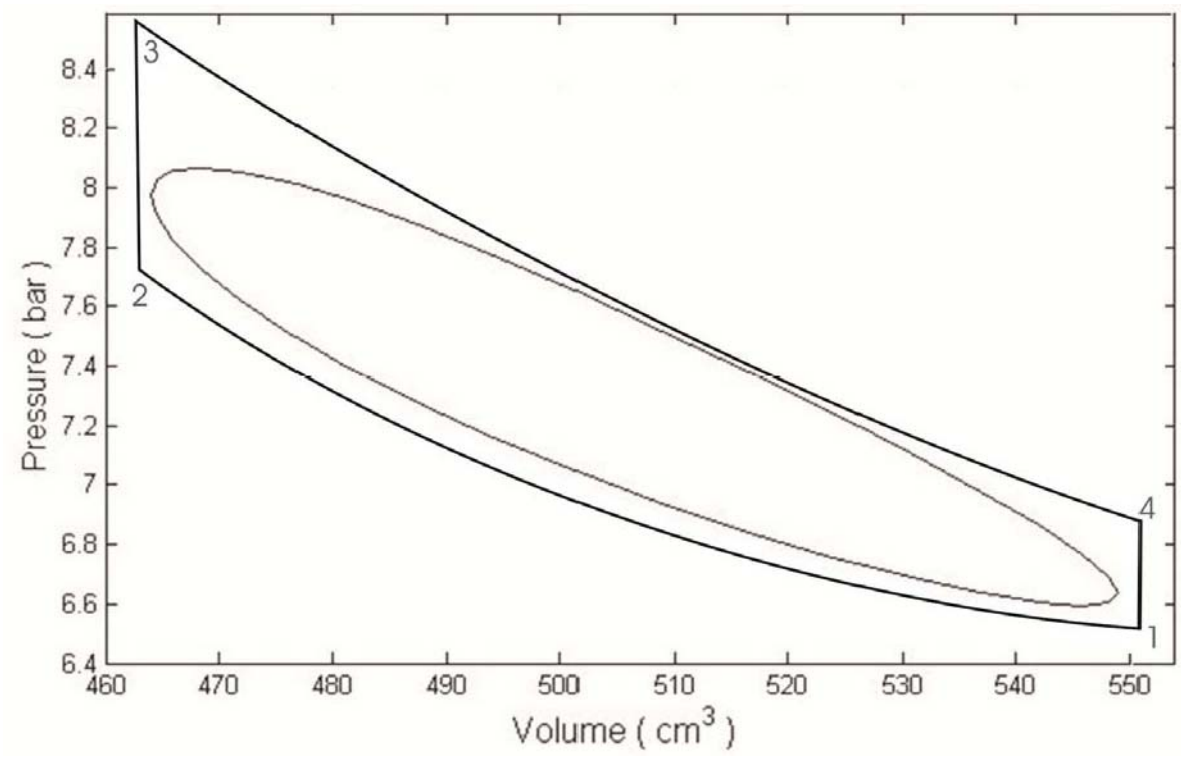

Figure 6: Actual engine P-V diagram versus ideal engine. 


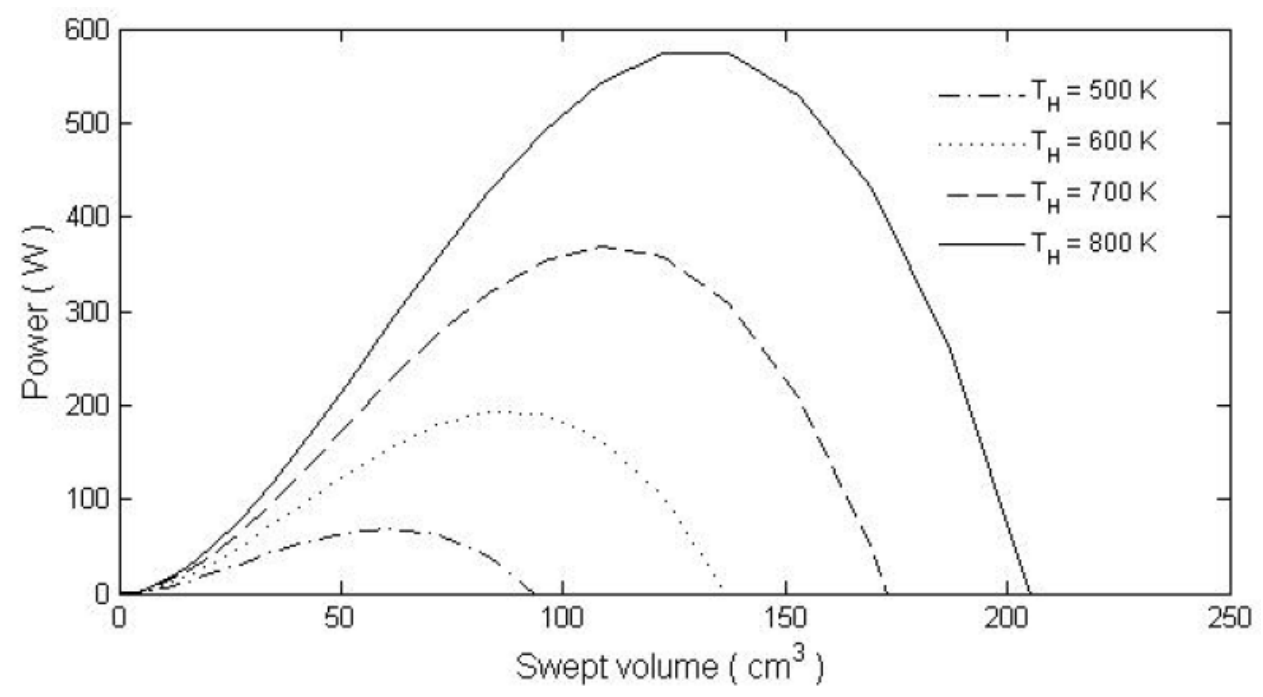

Figure 7: The effect of swept volume and heater temperature on power output ( freq $=90 \mathrm{~Hz}$ ).

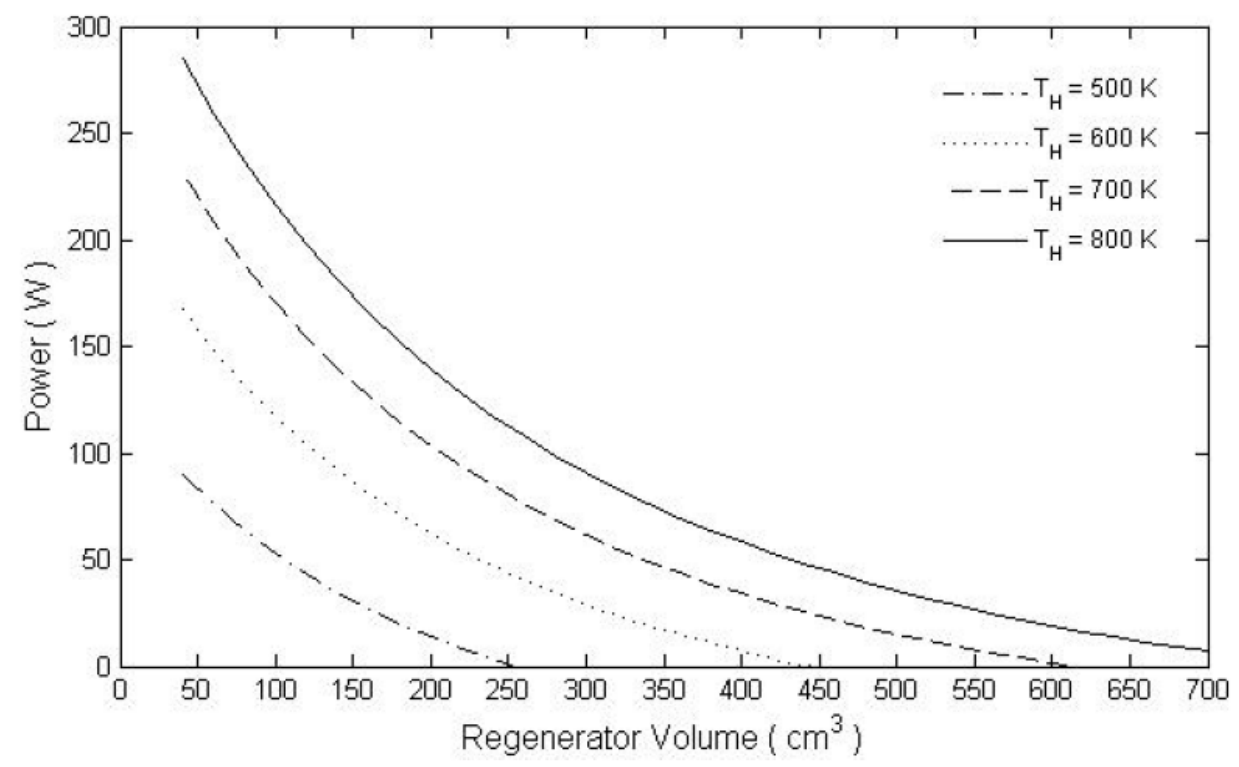

Figure 8: Relationship between dead volume and engine power (frequency $=90 \mathrm{~Hz}$ ).

\subsubsection{Effect of Heater Temperature}

The effect of heater temperature on the thermal efficiency for several values of swept volumes is displayed in Figure 10. The results in Figure $\mathbf{1 0}$ show that the thermal efficiency of the engine is monotonically increased with an increase in heater temperature. Furthermore, increasing the swept volume requires higher heater temperature for the engine to deliver work. For example, for swept volume $76.3 \mathrm{~m}^{3}$, the engine start delivering work at heater temperature equals to $438 \mathrm{~K}$, while for swept volume equals to $171.6 \mathrm{~m}^{3}$, the heater temperature has to be $600 \mathrm{~K}$ for the engine to start delivering work. Finally, it is observed that the thermal efficiency starts to level off at high values of heater temperature.

\subsubsection{Effect of the Mean Pressure (Total Fluid Mass)}

Since the mean pressure is a key factor affecting the engine performance, its effect has been studied. Mean pressure is related to the total mass. The proportional relation between the power and the mean pressure can be seen in Figure 11. As it is clear that high output power will happen in very high pressure values which are impractical. Since increasing the mean pressure leads to an increase in the mass flow rate and the gas velocity, this leads to more energy loss by pressure drop. However, the engine power increases and there should be an optimal value of the total mass in the engine. 


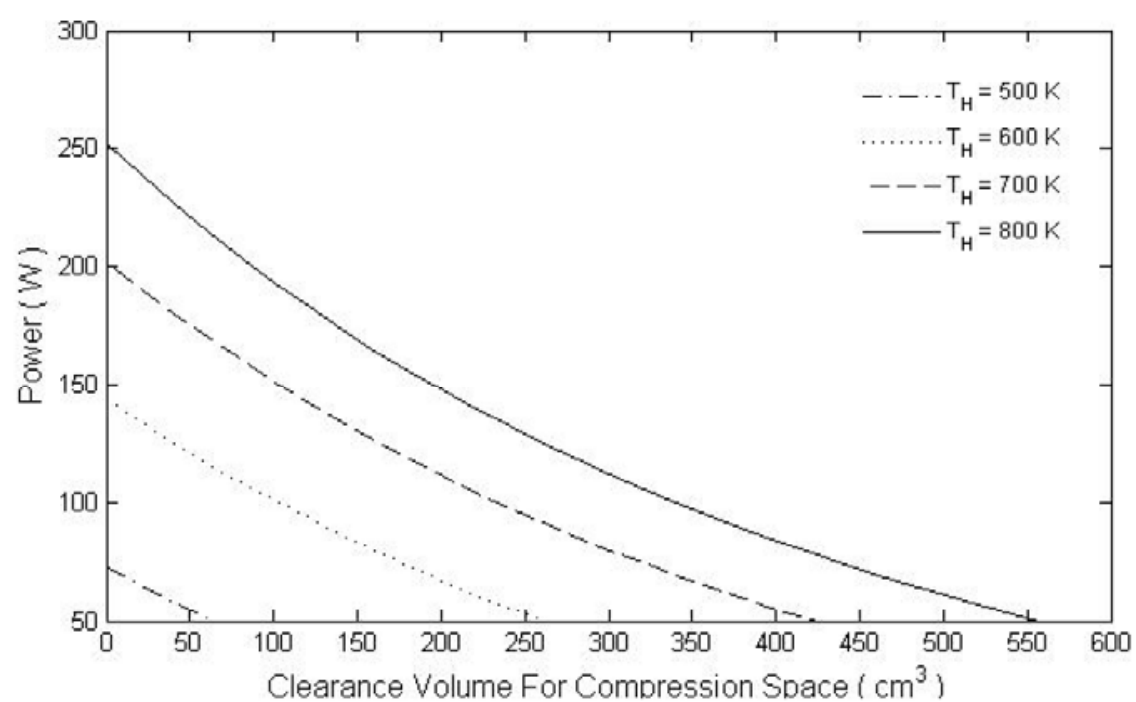

Top

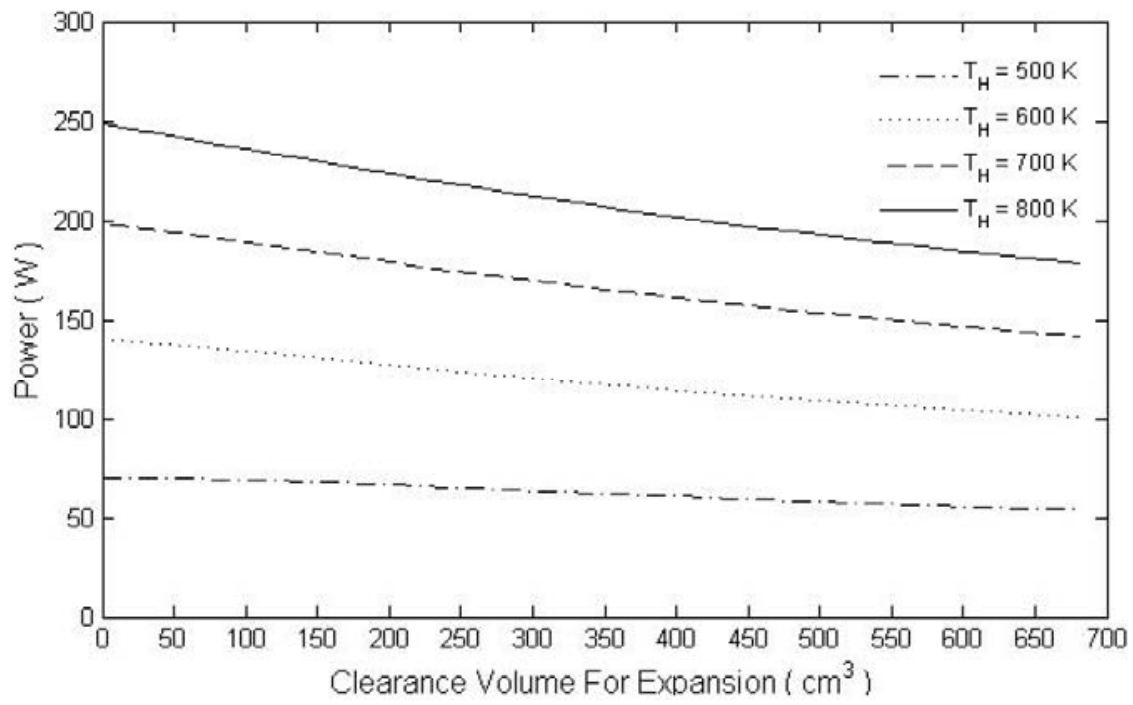

Bottom

Figure 9: effect of clearance volume on power output, Top: in compression space, Bottom: in expansion spaces.

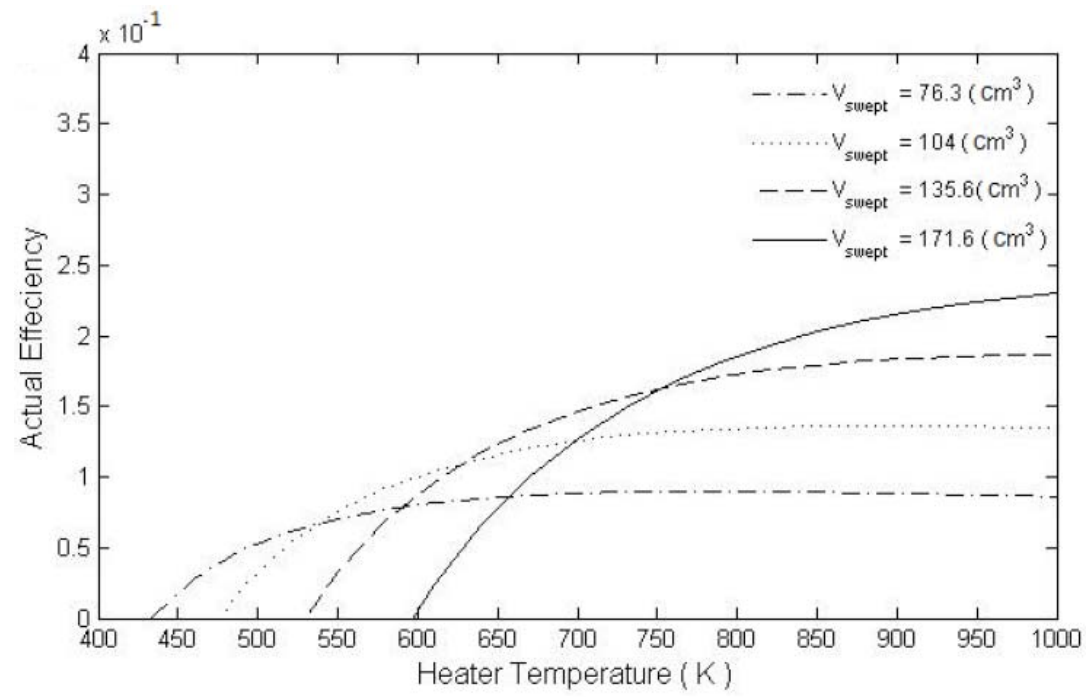

Figure 10: Influence of the heater temperature on the actual thermal efficiency. 


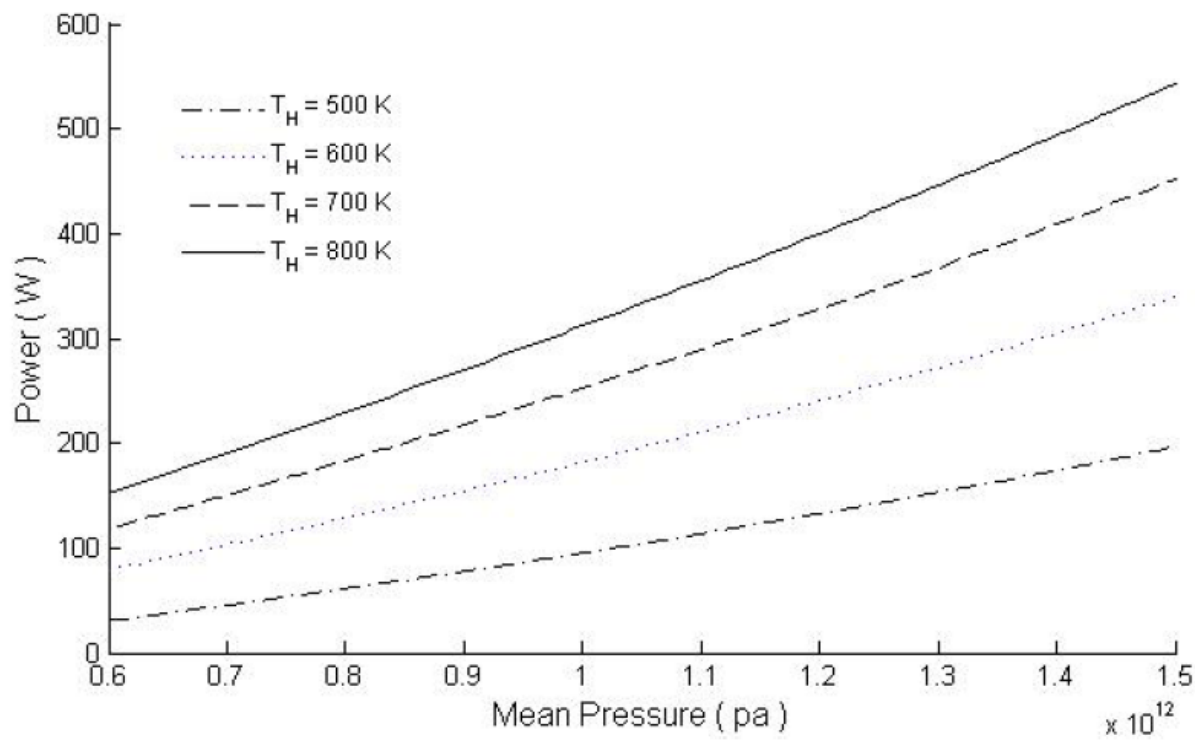

Figure 11: Effect of mean pressure on the output power for several values of heater temperature.
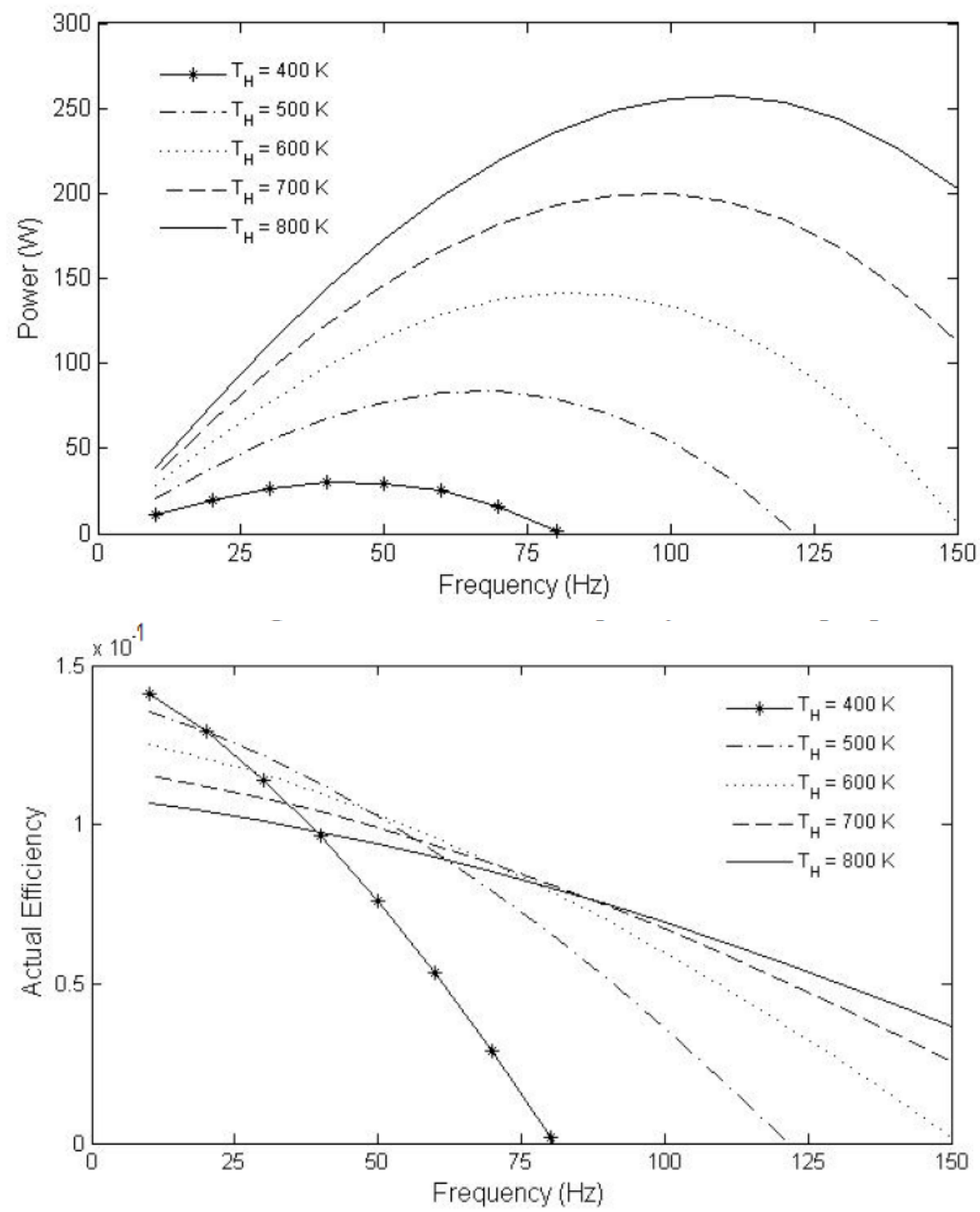

Figure 12: Influence of frequency on the output power. 


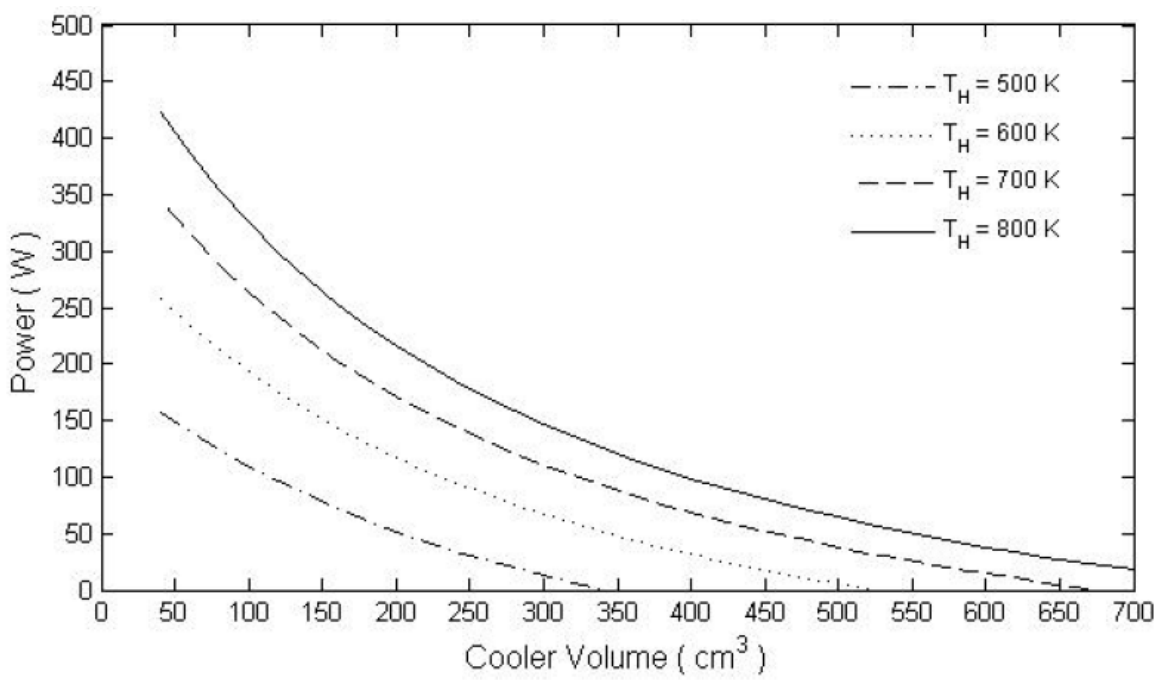

Top

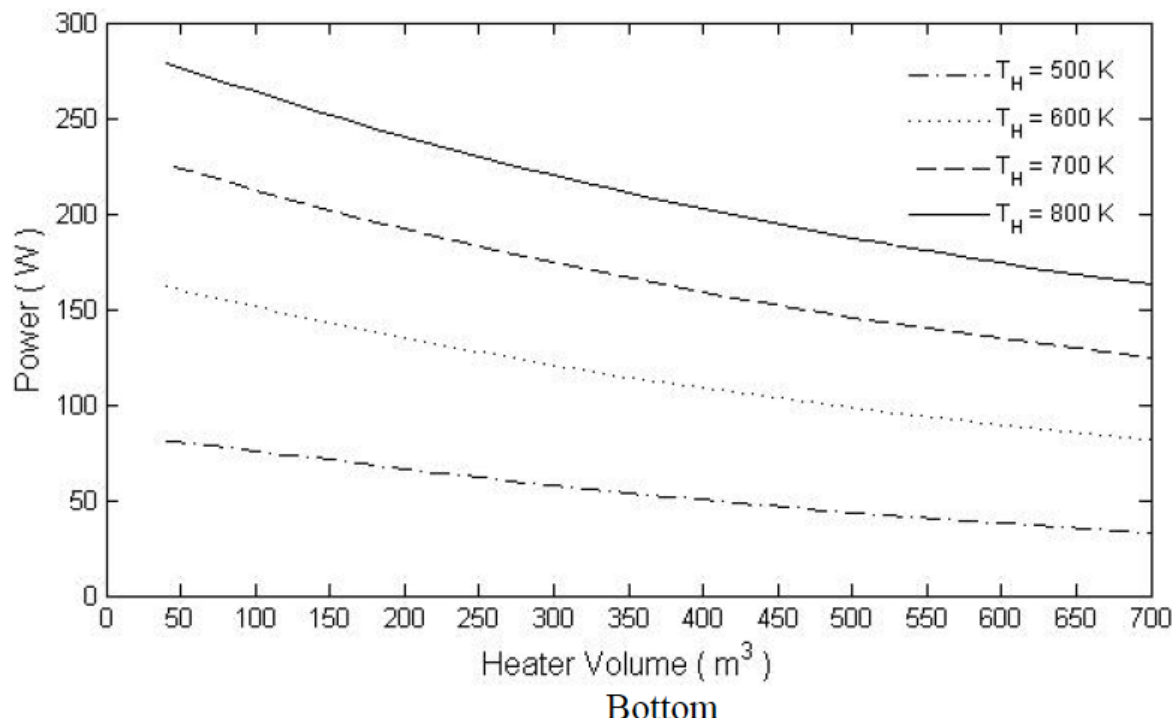

Figure 13: Relationship between volume and output power at frequency $90 \mathrm{~Hz}$ at swept volume $66.25 \mathrm{~cm}^{3}$. Top: Cooler volume, Bottom: Heater volume.

\subsubsection{Effect of Frequency}

Figure 12 shows the output power variations with the working frequency for several heater temperatures. As it can be seen in Figure $\mathbf{1 2}$ that by increasing the frequency, the output power increases until an optimal value is reached. This behavior can be explained as follows; power increases with increasing frequency, on the other hand, power loss is high in high speed. At first by increasing the rotational speed, the power grows with a positive gradient but after reaching its maximum it starts to drop because the engine loss starts to grow more dramatically Also, it is noticeable that the power increases with the increase in heater temperature. Numerical results show that increasing heater temperature shift the optimal frequency to the right. The power output is significantly increased as the heat source temperature is elevated. It is also found that the rate of increase in the power output is high in highspeed regime than in low-speed regime. Therefore, increasing the heat source temperature is only effective if the engine is designed to operate at high speed.

\subsubsection{Effect of Heater and Cooler Geometry}

Heater and cooler are very important to a Stirling engine since they connect it to the heat source and sink. Heat exchangers should have excellent ability to transfer heat to or from the engine. Heat exchanger volume is considered crucial factor in heat exchanger design. The geometry of heat exchangers plays a major role in the design of Stirling engine and should be investigated carefully. To investigate the effect of the heater and cooler geometry on the output power, simulations are carried out. Results are obtained by changing the area of the heater and cooler. To 
demonstrate the relationships between the cooler and heater tube diameter respectively, specific conditions of $66.2 \mathrm{~cm}^{3}$ swept volume and $0.45 \mathrm{~m}$ tube length are used. Curves presented in Figure 13 (top and bottom) indicate that the power output is inversely proportional to the tube diameter. This is due to the fact that smaller tubes lead to a higher friction factor to the flow. Similar behavior is observed for the cooler. The heat transfer area plays a major role in determining the effectiveness of the heat exchangers. So by choosing more efficient heat exchangers, the performance of the engine improves. On the other hand, pumping loss is another important issue to the performance of cooler, heater and specially regenerator which causes design limitations.

\section{CONCLUSION}

In this article, a thermodynamic model for alpha type mean differential Stirling engines that takes thermal losses into account utilizing Ross Yoke drive mechanism has been developed. Thermal losses by external, internal conduction and pressure losses in the regenerator are carefully examined. The effect of these losses depends on the geometric and physical parameters of the engine. The results of this study show that the power output can be maximized if optimal values of engine parameters are chosen. The results show that the regenerator performance is vital for a Stirling engine due to its effect on the thermal efficiency. Finally, it is found that the volumes of heat exchanger played a major role and should be designed carefully.

\section{NOMENCLATURE}

$$
\begin{aligned}
& \text { A } \quad=\operatorname{area}\left(\mathrm{m}^{2}\right) \\
& A_{w t} \quad=\text { wetted area }\left(\mathrm{m}^{2}\right) \\
& \mathrm{C}_{\mathrm{p}}=\text { specific heat for constant pressure }(\mathrm{J} / \mathrm{kgK}) \\
& \text { Cv = specific heat for constant volume }(\mathrm{J} / \mathrm{kgK}) \\
& \mathrm{d}=\text { hydrualic diamter }(\mathrm{m}) \\
& \text { f } \quad \text { = friction coefficient } \\
& \text { g = acceleration gravity }\left(\mathrm{m} / \mathrm{s}^{2}\right) \\
& \mathrm{h}=\text { coefficient for convective heat transfer } \\
& \left(\mathrm{W} / \mathrm{m}^{2} \mathrm{~K}\right) \\
& \mathrm{L}=\text { Length }(\mathrm{m}) \\
& \mathrm{m}=\operatorname{mass}(\mathrm{kg})
\end{aligned}
$$

$$
\begin{array}{ll}
\dot{\mathrm{m}} & =\text { mass flow rate }(\mathrm{kg} / \mathrm{s}) \\
\mathrm{N} & =\text { engine speed }(\mathrm{Hz}) \\
\mathrm{NTU} & =\text { number of transfer units } \\
\mathrm{p} & =\text { pressure }(\mathrm{Pa}) \\
\mathrm{pmean} & =\text { engine mean pressure }(\mathrm{Pa}) \\
\Delta \mathrm{p} & =\text { pressure drop }(\mathrm{Pa}) \\
\mathrm{Q} & =\text { heat }(\text { Joule }) \\
\mathrm{R} & =\text { gas constant }(\mathrm{J} / \mathrm{mol} \cdot \mathrm{K}) \\
\mathrm{Re} & =\text { Rynolds number } \\
\mathrm{St} & =\text { Stanton number } \\
\mathrm{T} & =\text { temperature }(\mathrm{K}) \\
\mathrm{U} & =\text { velocity of the working gas }(\mathrm{m} / \mathrm{s}) \\
\mathrm{V} & =\text { volume }\left(\mathrm{m}^{3}\right) \\
\varepsilon & =\text { regeneration effectiveness } \\
\gamma & =\text { isentropic gas index } \\
\eta & =\text { thermal efficiency } \\
\rho & =\text { density of the working gas }
\end{array}
$$

\section{Subscript}

C $\quad$ = Compression section

e $\quad=$ Expansion section

$\mathrm{h} \quad=$ Heater section

$\mathrm{k} \quad=$ Cooler section

$\mathrm{e} \quad=$ Oulet

$r \quad=$ Regenerator section

$\mathrm{i} \quad=$ Inlet

\section{REFERENCES}

[1] Stirling Robert. Patent no. 4081, Stirling air engine and the heat regenerator 1816.

[2] Bataineh K, Fayez N. Analysis of thermal performance of building attached sunspace. Energy Buildings 2011; 43(8): 1863-68.

[3] Bataineh KM, Dalalah D. Optimal Configuration for Design of Stand-Alone PV System. Smart Grid Renewable Energy 2012; 3(2). 
[4] Bataineh K, Fayez N. Thermal Performance of Building Attached Sunspace in Jordan Climate. The 1st International Nuclear and Renewable Energy Conference "(INREC'10) Amman, Jordan 2010.

[5] Popescu G, Radcenco V, Costea M, Feidt M. Thermodynamic optimization in the finished time of Stirling engine [Optimisation thermodynamique en temps fini du moteur de Stirling endo-et exoirre 'versible]. Rev Ge'n Therm 1996; 35: 656-61. http://dx.doi.org/10.1016/S0035-3159(96)80062-6

[6] Kaushik SC, Kumar S. Finite time thermodynamic analysis of endoreversible Stirling heat engine with regenerative losses. Energy 2000; 25: 989-1003. http://dx.doi.org/10.1016/S0360-5442(00)00023-2

[7] Wang Jin T, Chen J. Influence of several irreversible losses on the performance of a ferroelectric Stirling refrigerationcycle. Appl Energy 2002; 72: 495-11. http://dx.doi.org/10.1016/S0306-2619(02)00026-0

[8] Kongtragool B, Wongwises S. Thermodynamic analysis of a Stirling engine including dead volumes of hot space, cold space and regenerator. Renew Energy 2006; 31: 345-59. http://dx.doi.org/10.1016/j.renene.2005.03.012

[9] Tlili I, Timoumi Y, Nasrallah SB. Analysis and design consideration of mean temperature differentialStirling engine for solar application. Renewable Energy 2008; 33: 1911-21. http://dx.doi.org/10.1016/j.renene.2007.09.024

[10] Andersen SK, Carlsen H, Thomsen PG. Numerical study on optimal Stirling engine regenerator matrix designs taking into account the effects of matrix temperature oscillations. Energy Convers Manage 2006; 47: 894-908. http://dx.doi.org/10.1016/j.enconman.2005.06.006

[11] Andersen SK, Carlsen H, Thomsen PG. Preliminary Results from Simulations of Temperature Oscillations in Stirling Engine Regenerator Matrices. Energy 2006; 31(10-11): 1371-83.
[12] Andersen Sk, Carlsen H, Thomsen PG. Simulation of Temperature Fluctuations in Stirling Engine Regenerator Matrices, Proceedings of $11^{\text {th }}$ international Stirling engine Conference 2003.

[13] Urieli I, Berchowitz D. Stirling cycle engine analysis. Bristol: Adam Hilger 1984.

[14] Wu F, Chen L, Wu C, Sun F. Optimum performance of irreversible Stirling engine with imperfect regeneration. Energy Convers Manage 1998; 39: 727-32. http://dx.doi.org/10.1016/S0196-8904(97)10036-X

[15] Costa M, Petrescu S, Harman C. The effect of irreversibilities on solar Stirling engine cycle performance. Energy Convers Manage 1999; 40: 1723-31 http://dx.doi.org/10.1016/S0196-8904(99)00065-5

[16] Cheng $\mathrm{C}-\mathrm{H}$, Yang $\mathrm{H}-\mathrm{S}$. Analytical model for predicting the effect of operating speed on shaft power output of Stirling engines. Energy 2011; 36: 5899-908. http://dx.doi.org/10.1016/j.energy.2011.08.033

[17] Tlili I, Timoumi Y, Ben Nasrallah S. Numerical simulation and losses analysis in a Stirling engine. Heat Technol 2006; 24 97-105.

[18] Schmidt G. The Theory of Lehmann's Calorimetric Machine Z. Ver. Dtsch Ing 1871; 15: part 1.

[19] Organ AJ. The regenerator and the Stirling engine by. London: Mechanical Engineering Publications Limited 1997.

[20] Finkelstein T. Insights into the thermodynamics of Stirling cycle machines. AIAA-94-3951-CP 1994; 1829-34.

[21] Kolin I. Stirling motor: history-theory-practice. Dubrovnik: Inter University Center 1991.

[22] Organ AJ. Solution of the conjugate heat transfer problem. Proc Inst Mech Eng (Pt. C) 1997; 211: 17-24.

[23] Kays WM, London AL. Compact heat exchangers. McGrawHill 1964. 